\title{
Cytotoxic, Antioxidant and Antifatigue Activities of 8 Cultivated Varietiesmyricarubra Kernel and Residue Extracts
}

\author{
Ya-Si Huang, Jia-Sheng Wu, Yong Wang, Ke Yuan* \\ The Nurturing Station for the State Key Laboratory of Subtropical Silviculture, Zhejiang Agriculture and Forestry University, Lin’an, China \\ *Corresponding author: yuan_ke001@126.com
}

Received September 17, 2014; Revised November 06, 2014; Accepted November 17, 2014

\begin{abstract}
The development of bayberry product has been long restricted to the under utilised residue and the waste of the kernels. In this paper, we aimed to investigate whether the waste part of bayberry produced during juice processing may possess potent beneficial role to use for our health promotion. In fruit residue and kernels parts from eight different cultivars, determination of cyaniding-3-O-glucoiside (C3G) levels using HPLC (high performance liquid chromatography), various functional assays including antioxidant, and antifungal assays in vitro, cytotoxic assays and also antifatigue assays in vivo using reducing testes, rectangular cantilever method, small microtiter-plate method and mice loaded swimming test, respectively. The results of the HPLC method showed the extracts of residue were rich in cyaniding-3-O-glucoside, especially in Myricarubra Sieb. Et Zucc. cv. Biqi (212.8 mg. $\mathrm{g}^{-1} \mathrm{from}$ Ninghai and $185.7 \mathrm{mg} \cdot \mathrm{g}^{-1}$ from Yuyao). The results of the activity experiments showed the TE values of the extract from Biqi were between 334 and $506 \mathrm{mmol} \cdot \mathrm{g}^{-1}$ detected by different methods. The duration of loaded swimming to exhaust prolonged from $614 \pm 158$ s to $1012 \pm 205$ s. The MIC (minimal inhibitory concentration) values of different species of kernels extracts against 8 different fungi ranged from 0.5000 to $0.0625 \mathrm{mg} \cdot \mathrm{mL}^{-1}$. The LC50 were from $49-$ $316 \mu \mathrm{g} \cdot \mathrm{mL}^{-1}$. In conclusion, the waste part of bayberry produced during juice processing, the residue and kernels, is of potential application value. However, further study is required.
\end{abstract}

Keywords: anthocyanin, antioxidant, antifungal, cytotoxic, antifatigue

Cite This Article: Ya-Si Huang, Jia-Sheng Wu, Yong Wang, and Ke Yuan, “Cytotoxic, Antioxidant and Antifatigue Activities of 8 Cultivated Varieties myricarubra Kernel and Residue Extracts.” Journal of Food and Nutrition Research, vol. 2, no. 12 (2014): 931-937. doi: 10.12691/jfnr-2-12-12.

\section{Introduction}

The Myricaceae plant Myricarubra Sieb. Et Zucc., which has a long cultivating history and high yield in China, is one of the most important edible fruits with a high anthocyanin content. Many researchers proved that anthocyanins are very helpful in preventing glycuresis [15] and gastric cancer $[6,7,8]$. However, not every anthocyanin has anticancer or antidiabetics biological activity. Cyanidin-3-O-glucoside (C3G) is one of the most common anthocyanins. Previous research $[9,10,11]$ proved that C3G had obvious effects on treating glycuresis and gastric cancer. It has been reported that Myricarubra juice has a high content of C3G $[12,13]$. However, it is very difficult to develop and utilize Myricarubra because of its high sugar content. The exploitation of Myricarubra is seriously impaired by the waste of hundreds and thousands of tons of its residues and kernels, the disposal of which is very difficult [14]. Furthermore, because of the large varieties of Myricarubra, it is common for us to ignore the best varieties in food industry. In this paper the extracts of 8 cultivated varieties of Myricarubra were prepared and analyzed by HPLC (high performance liquid chromatography). Meanwhile, the antioxidant, antifungal, cytotoxic, and antifatigue activities of the extracts were investigated. These results will help us to seek out the best varieties of Myricarubra and also help us to understand the potential value of its two waste materials.

\section{Materials and Methods}

\subsection{Materials and Chemicals}

Myricarubra fruit of 8 cultivars were obtained in Zhejiang Province, China in June, 2011. Myricarubra Sieb. Et Zucc.cv. Biqi ${ }^{1}$, Myricarubra Sieb. Et Zucc.cv. Tanmei and Myricarubra Sieb. Et Zucc.cv. Shuijing were from Ninghai, Myricarubra Sieb. Et Zucc.cv. Biqi ${ }^{2}$ was from Yuyao, Myricarubra Sieb. Et Zucc.cv. Dongkui from Taizhou, Myricarubra Sieb. Et Zucc.cv. Ding-ao from Wenzhou, Myricarubra Sieb. Et Zucc.cv. Wandao from Zhoushan, and wild species Myricarubra Sieb. Et Zucc. was from Lin'an, respectively. Fruit of each cultivar was stored at $-20^{\circ} \mathrm{C}$ until analysis. Fungal strains, namely Fusariumgraminearum Schwabe, Fusariumgraminearum, Exerohilumturcicum Pass, Rhizoctoniasolani Kühn, Botrytis cinerea, Valsamali, Sclerotiniasclerotiorum and 
Fusariumoxysporum f. sp. Vasinfectum are provided by microbiological lab of Zhejiang Agriculture and Forestry University. Male mice were purchased from Institute of Materia Medica, Zhejiang Academy of Medical Sciences, China. Artemiasalina was purchased from Fengnian Aquacultrue Co., Ltd Tianjin, China.

Standards of C3G, rutin, gallate acid were purchased from the National Assaying Institute for the Pharmaceutical and Biological Products. DPPH (1, 1diphenyl-2-picrylhydrazyl); TPTZ (2, 4, 6-Tris (2pyridyl)-s-triazine); Trolox (6-hydroxy-2, 5, 7, 8tetramethylchroman-2-carboxylic acid) were purchased from Sigma-Aldrich Co. (St._Louis, MO). Methanol was chromatographically pure and the other organic solvents and chemicals used in this study were of analytical pure.

\subsection{Preparation of Purified Anthocyanins Extracts (PAEs)}

Approximately $500 \mathrm{~g}$ of Myricarubra fruit of each cultivar was denucleated and mashed, respectively. The squeezed residue was extracted twice with the ratio of 1:2 (v/v) $\mathrm{pH} 3$ by $50 \%$ ethanol solutions using ultrasonic extraction for $1 \mathrm{~h}$ and Rotary-evaporated method under vacuum at $60^{\circ} \mathrm{C}$ until the ethanol was evaporated completely. Then it was passed through resin columns (Diaion, HP2 MGL, Mitsubishi Co of Japan, $6 \mathrm{~cm} \times 30$ $\mathrm{cm}$ ) depending on the adsorbent capability of each resin. C3G was adsorbed onto the column, and sugar, acids and other water-soluble compounds were eluted with more than $2 \mathrm{BV}$ of distilled water until the wash water was clear [15]. The adsorbed material was then eluted with acidified $60 \%$ ethanol (v/v, pH 3). The eluent was concentrated on a rotary evaporator under $60^{\circ} \mathrm{C}$ until the pigment powder was prepared and stored in a cool dry place before analysis. The crystal Myricarubra had the color of white and contained no anthocyanidin, so we didn't get its extracts.

\subsection{Preparation of Extracts From Kernels (Eks)}

The 8 bayberry kernels of cleaned and dried varieties were screened through mesh size of 60 after shattered, then stored in a dry place. Weigh accurately $1.00 \mathrm{~g}$

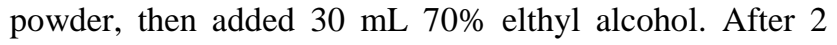
times of ultrasonic extraction ( $1 \mathrm{~h}$ each time), the extraction solution was amalgamated and concentrated under reduced pressure at $60^{\circ} \mathrm{C}$, and then brought to 10 $\mathrm{mL}$ with $70 \%$ chromatographically pure elthyl. The solution was kept in cold storage before analysis.

\subsection{HPLC Analysis}

Contents of C3Gs were analyzed with a Waters 2695 high performance liquid chromatograph linked simultaneously to a Waters 2996 photodiode array detector. All samples were filtered through a $0.45 \mu \mathrm{m}$ Millipore membrane filter before injection. A $10 \mu \mathrm{L}$ aliquot was separated by a SunFire-C18 (Waters, USA) column $(250 \mathrm{~mm} \times 4.6 \mathrm{~mm}, 5 \mu \mathrm{m})$ at $30^{\circ} \mathrm{C}$. The mobile phase consisted of solvent A (2\% hydrochloric acid in methyl alcohol) and solvent B (water, methyl alcohol, acetonitrile, acetic acid $=$ 160:90:90:40, v/v/v/v). Using isocratic elution with $\mathrm{A}: \mathrm{B}=93: 7$ with the flow rate 1.0 $\mathrm{mL} \cdot \mathrm{min}^{-1}$, C3G was detected at $530 \mathrm{~nm}$.

\subsection{DPPH Assaying Method}

The DPPH assay was utilized by 96-well plates with some modifications [16]. The absorbance in this study was measured by automatic microplate reader (Infinite M 200 Pro, Tecan). The PAEs of $1.00 \mathrm{mg}$ from 7 different cultivars were dissolved with $10 \mathrm{~mL}$ absolute ethyl alcohol, respectively. 5, 10, 15, 20, $25 \mu \mathrm{L}$ of PAEs and EKs solution were added to 96-well microplates and then $195,190,185,180,175 \mu \mathrm{L}$ absolute ethyl alcohol was added to each well respectively. $50 \mu \mathrm{L}$ DPPH were added to the microplates and incubated at $25^{\circ} \mathrm{C}$ for 30 minutes, then the ultraviolet absorption (As) was determined at 517 $\mathrm{nm}$. The antioxidant activity (\%) of radical-scavengers was calculated as (As-Ar/Ao) $\times 100 \%$, where As and $\mathrm{Ar}$ are the absorbance of the sample and control, respectively, at $517 \mathrm{~nm}$. Trolox was used as the standard. Results were expressed as TE (mmol Trolox equivalents) per g dry weight.

\subsection{FRAP (Ferric Reducing Antioxidant Power) Assaying Method}

The reducing abilities were measured by DU 800 visible ultraviolet spectrophotometer (Beckman Coulter Inc,) [17]. The FRAP assay was carried out, where the FRAP reagent was made from $10 \mathrm{mmol} \cdot \mathrm{L}^{-1} \mathrm{TPTZ}$ and 20 $\mathrm{mmol} \cdot \mathrm{L}^{-1}$ ferric chloride in $0.1 \mathrm{~mol} \cdot \mathrm{L}^{-1}$ sodium acetate buffer (1:1:10, v/v/v, pH 3.6). $10 \mathrm{~min}$ after the combination of $150 \mu \mathrm{L}$ FRAP with $50 \mu \mathrm{L}$ solution $(0.2$ $\mathrm{mg} \cdot \mathrm{mL}^{-1}$, absolute ethyl alcohol), the absorbance at 593 nm was measured, where the standard curve was constructed using a linear concentration of Trolox. Results were expressed as TEper g dry weight.

\subsection{TRP (Total Reducing Power) Assay Method}

The TRPs were determined according to the method procedure described by Oyaizu [18]. Each $500 \mu \mathrm{L}$ solution (0.2 $\mathrm{mg} \cdot \mathrm{mL}^{-1}$, absolute ethyl alcohol), sodium phosphate buffer (2.5 mL, $0.2 \mathrm{~mol} \cdot \mathrm{L}^{-1}, \mathrm{pH}$ 6.6) and potassium ferricyanide $\left(2.5 \mathrm{~mL}, 10 \mathrm{mg} \cdot \mathrm{mL}^{-1}\right)$ were mixed and incubated at $50^{\circ} \mathrm{C}$ for $30 \mathrm{~min}$. Trichloroacetic acid (2.5 $\mathrm{mL}, 100 \mathrm{mg} \cdot \mathrm{mL}^{-1}$ ) was added to the mixture and centrifuged at $4000 \mathrm{rpm}$ for $10 \mathrm{~min}$. The supernatant $(2.5$ $\mathrm{mL}$ ) was mixed with distilled water $(2.5 \mathrm{~mL})$ and $0.1 \%$ ferric chloride $(0.5 \mathrm{~mL})$, and then its absorbance was measured at $700 \mathrm{~nm}$ against a blank. Trolox was used as a control and the results were expressed as TE per g dry weight.

\subsection{Antifungal Experiment and MIC (Minimal Inhibitory Concentration) Measurement}

This research improved the method of Zhang, by evaluating antifungal activity of PAEs and EKs [19]. Diluted EKs and PAEs solution with 70\% elthyl-alcohol in multiples to sample solutions with concentrations as 1.000, 0.500, 0.250, 0.125, 0.0625 and $0.03125 \mathrm{mg} \cdot \mathrm{mL}^{-1}$. $5 \mathrm{~mL}$ well prepared PDA (potato dextrose agar) culture 
medium was added to test tubes, and was made to slant culture medium after $20 \mathrm{~min}$ sterilization at $121^{\circ} \mathrm{C}$, then $500 \mu \mathrm{L}$ sample solutions of different concentrations were added to the cooling culture medium. After sample solvent was volatilized, 8 kinds of fungi were inoculated with streak-plating method. The inoculated medium was sealed and cultivated at $25^{\circ} \mathrm{C}$, then observed the growing state of Hyphae after 48 h. 3 groups of parallel experiments were carried out for each sample. The minimal sample concentration was expressed as MIC.

\subsection{Brine Shrimp Lethality Assay}

The brine shrimp toxicity was assayed by modified small microtiter-plate method using brine shrimp Artemiasalina as a test organism [20]. 0.5, 1, 2, 4, 8, 10 $\mu \mathrm{L}$ PAEs solution $\left(0.10 \mathrm{mg} \cdot \mathrm{mL}^{-1}\right.$ of the distilled water $)$ and EKs solution $\left(0.10 \mathrm{~g} \cdot \mathrm{mL}^{-1}\right.$ of the distilled water) were added into the microtiter-plate, and then a suspension of Artemiasalina containing 15-20 organisms (199.5, 199, 198, 196, 192, $190 \mu \mathrm{L})$ was added to each well, respectively. Distilled water in the same volumes was used to substitute for the sample as the negative controls, respectively. The number of organisms in each well was recorded in time and shielded from light. Being incubated at $28 \pm 0.5^{\circ} \mathrm{C}$ for $24 \mathrm{~h}$, the number was recorded again. The corrected mortality rate was calculated according to the following formula: Corrected mortality rate $(\%)=[(\mathrm{T}-$ $\mathrm{C}) /(1-\mathrm{C})] \times 100 \%$, where $\mathrm{T}$ was the mortality rate of the treatment and $\mathrm{C}$ was the mortality rate of the negative control. The results were expressed as $\mathrm{LC}_{50}$, the concentration which corrected mortality rate was $50 \%$.

\subsection{In Vivo Antifatigue Effect}

This article estimated the in vivo antifatigue activity with mice loaded swimming experiment [21]. Several experimental mice with $20 \pm 2$ g weights which had adapted to the lab-environment for one week were randomly assigned to 3 experimental groups and each blank group consisting of dozens of mice. In vivo antifatigue effect of EKs were negative in preliminary experiment and PAEs from Biqi ${ }^{1}$ were prepared into the solutions with 3 concentrations (high concentration, $0.3320 \mathrm{mg} \cdot \mathrm{mL}^{-1}$; middle concentration, $0.2656 \mathrm{mg} \cdot \mathrm{mL}^{-1}$; low concentration, $0.1992 \mathrm{mg} \cdot \mathrm{mL}^{-1}$ ) with sodium carboxy methyl cellulose, and then the mixed solutions were tested with sodium carboxy methyl cellulose as control sample. The experimental mice were lavaged and weighted with $0.4 \mathrm{~mL}$ sample every $24 \mathrm{~h}$, and when the mice weights approached to $30 \mathrm{~g}$, the lavage dosage was increased to $0.6 \mathrm{~mL}$. By the time the intragastric administration was carried out for $30 \mathrm{~d}$, the antifatigue ability of mice was determined by loaded swimming. After treated with PAEs from $\mathrm{Biqi}^{1}$ for $30 \mathrm{~min}$, the experimental mice were allowed to swim in a swimming tank (volume of water, 50 $\mathrm{cm} \times 35 \mathrm{~cm} \times 40 \mathrm{~cm}$; water temperature, $25 \pm 0.5^{\circ} \mathrm{C}$ ) with a $5 \%$ mice weight lead sheath attached to the root of tails, and the time of mice exhaustion to death was recorded by stopwatch from the start of the swimming until the heads of mice were drowned beneath water for $10 \mathrm{~s}$ without moving.

\subsection{Statistical Analysis}

Each experiment was carried out in triplicate. Data were analyzed using the One-way ANOVA of SPSS.19 (Statistical Package for Social Science Institute, Cary, N.C.). Significant differences $(p<0.05)$ between mean values were determined using Duncan's multiple-range tests.

\section{Results and Discussion}

\subsection{Determination of C3G Content}

HPLC results show that, apart from the EKs and Shuijing (crystal Myricarubra, which were free of anthocyanin), 7 kinds of anthocyanin bayberry extracts all displayed one main chromatography peak (taking up about $95 \%$ of the total chromatographic peak area) with the detection wavelength of $530 \mathrm{~nm}$, while other peaks took up rather small area. Main peak was determined to be C3G after a peak time comparison analysis with standard substance, and the result was similar to the previous research [12] which had not studied the content difference among cultivated varieties. From Figure 1, we found that among the PAEs from 7 cultivated varieties, Biqi had the largest content of C3G (212.8 $\mathrm{mg} \cdot \mathrm{g}^{-1}$ from Ninghai, and $185.7 \mathrm{mg} \cdot \mathrm{g}^{-1}$ from Yuyao) is 250 times than that of in juice [22].

Our research purified the anthocyanins from 8 cultivated varieties of Myricarubra with macroporous resin, and then PAEs free of carbohydrates were obtained, which were rich in property-stable C3G. If applied in food additives, PAEs may avoid the loss of anthocyanins during processing and storage of bayberry, and the consumption-suitable range may be extended. PAEs from Biqi had the highest content of C3G, and the extraction rate of Biqi was found to be the highest of the 8 cultivated varieties. Considering these two factors, Biqi was more suitable for being exploited as food additives and healthcare products than other varieties.

\subsection{Antioxidant Activity Evaluation}

Table 1. The TE (mmol. $\mathrm{g}^{-1}$ ) value of PAEs (purified anthocyanins extracts)and the relativity analysis between C3G contents and antioxidant capacity of PAEs

\begin{tabular}{cccc}
\hline & DPPH & FRAP & TRP \\
\hline Dongkui & $275 \pm 19 \mathrm{c}$ & $352 \pm 25 \mathrm{~b}$ & $418 \pm 13 \mathrm{~b}$ \\
Ding-ao & $212 \pm 9.6 \mathrm{~d}$ & $294 \pm 8.5 \mathrm{c}$ & $333 \pm 12 \mathrm{c}$ \\
Wandao & $173 \pm 2.3 \mathrm{de}$ & $240 \pm 3.5 \mathrm{~d}$ & $276 \pm 13 \mathrm{~d}$ \\
Biqi $^{1}$ & $451 \pm 63 \mathrm{a}$ & $471 \pm 33 \mathrm{a}$ & $506 \pm 29 \mathrm{a}$ \\
Biqi $^{2}$ & $334 \pm 8.0 \mathrm{~b}$ & $361 \pm 17 \mathrm{~b}$ & $444 \pm 13 \mathrm{~b}$ \\
Tanmei & $159 \pm 19 \mathrm{e}$ & $159 \pm 17 \mathrm{e}$ & $245 \pm 9.6 \mathrm{e}$ \\
Wild species & $128 \pm 3.1 \mathrm{e}$ & $133 \pm 30 \mathrm{e}$ & $171 \pm 7.8 \mathrm{f}$ \\
\hline $\mathrm{R}^{2}$ & 0.888 & 0.961 & 0.967 \\
\hline
\end{tabular}

All the measurements were taken in triplicate and the results are expressed as mean values \pm standard deviations. Values followed by different letters within the same row represent significant differences at $\mathrm{P}$ $<0.05$.

Except crystal Myricarubra, the antioxidant activities of 7 PAEs and 8 EKs were detected by 3 different methods at the same time. Antioxidant activities of EKs were not found. And the result shown in Table 1 and Figure 2, was that 7 kinds of PAEs all had great free radical scavenging capacity and reducing capacity with good data consistency in the three methods. Compared with other varieties, PAEs from Biqi showed strongest scavenging activity of $\mathrm{DPPH}$ radicals and reducing 
capacity. Being both from Ninghai and Yuyao, the TE values were between 334 and $506 \mathrm{mmol} \cdot \mathrm{g}^{-1}$ detected different methods, and particularly, Biqi from Ninghai had TE value of more than $450 \mathrm{mmol} \cdot \mathrm{g}^{-1}$, by 3 Dongkui (275$\left.418 \mathrm{mmol} \cdot \mathrm{g}^{-1}\right)$, Ding-ao $\left(212-333 \mathrm{mmol} \cdot \mathrm{g}^{-1}\right)$ and Wandao $\left(173-276 \mathrm{mmol} \cdot \mathrm{g}^{-1}\right)$. Tanmei $\left(159-245 \mathrm{mmol} \cdot \mathrm{g}^{-1}\right)$ was the lowest among the 7 cultivated varieties, and the wild species was lower than all 7 cultivated varieties. Still, all of the PAEs showed much stronger antioxidant capacity than fresh fruits in previous researches. There might be two chief reasons: First, samples were processed by different methods. In this article the experimental materials were purified PAEs which contained more C3G than fresh fruits with stable properties. The analysis showed that the antioxidant capacity correlated closely with C3G contents, and the correlation coefficients $\left(\mathrm{R}^{2}\right)$ of 3 methods were $0.888,0.961$ and 0.967 , respectively, which indicated that C3G played an important role in antioxidant activity of PAEs from different bayberry varieties.
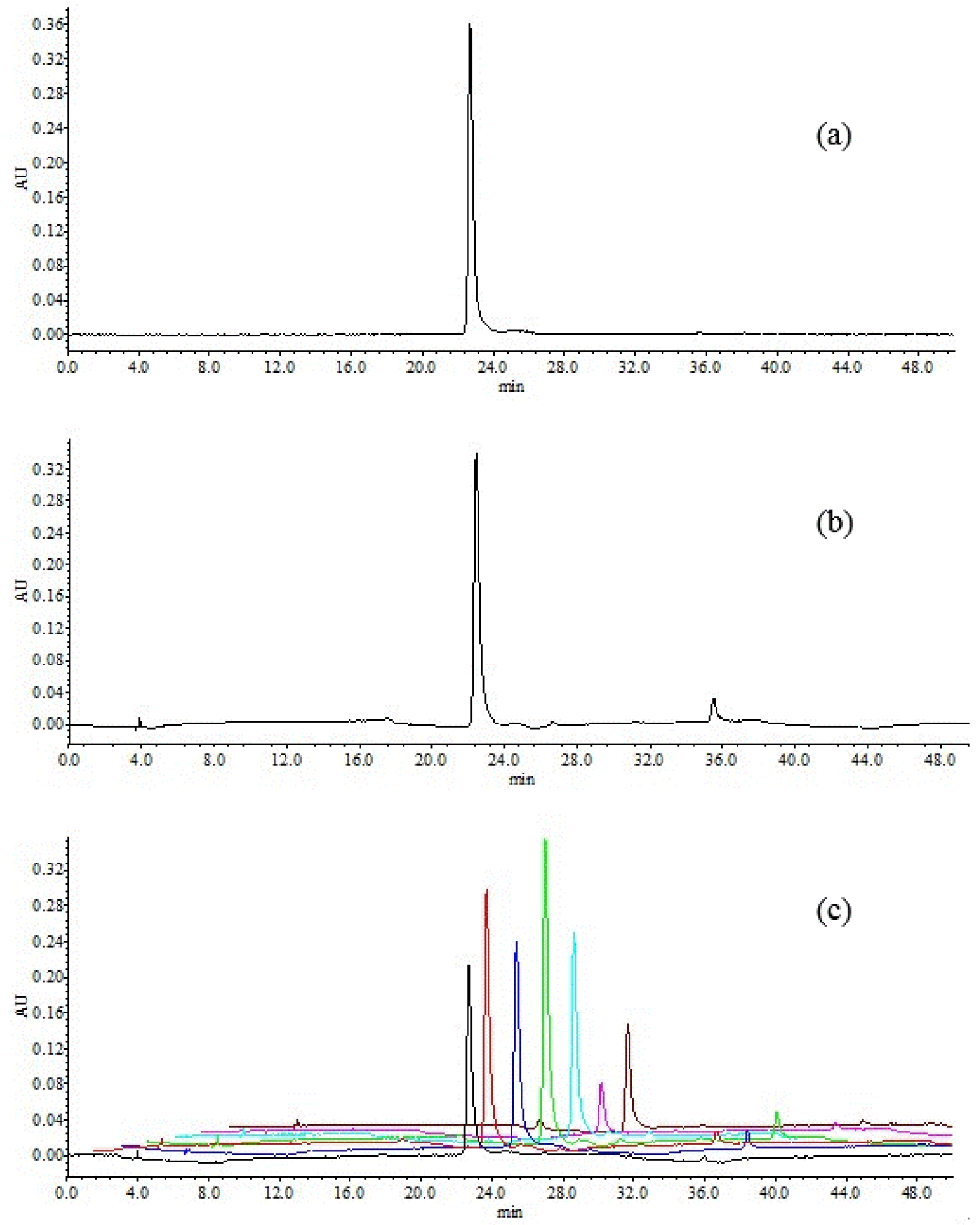

Figure 1. HPLC chromatogram (at $530 \mathrm{~nm}$ ) of a = C3G standard, b= C3G in Biqi ${ }^{1}$, c=C3G in different PAEs (purified anthocyanins extracts).(Chromatographic peaks from left to right in figure c indicated C3G contents from Wandao, Biqi ${ }^{2}$, Ding-ao, Biqi ${ }^{1}$, Dongkui, wild species, Tanmei, respectively.) 


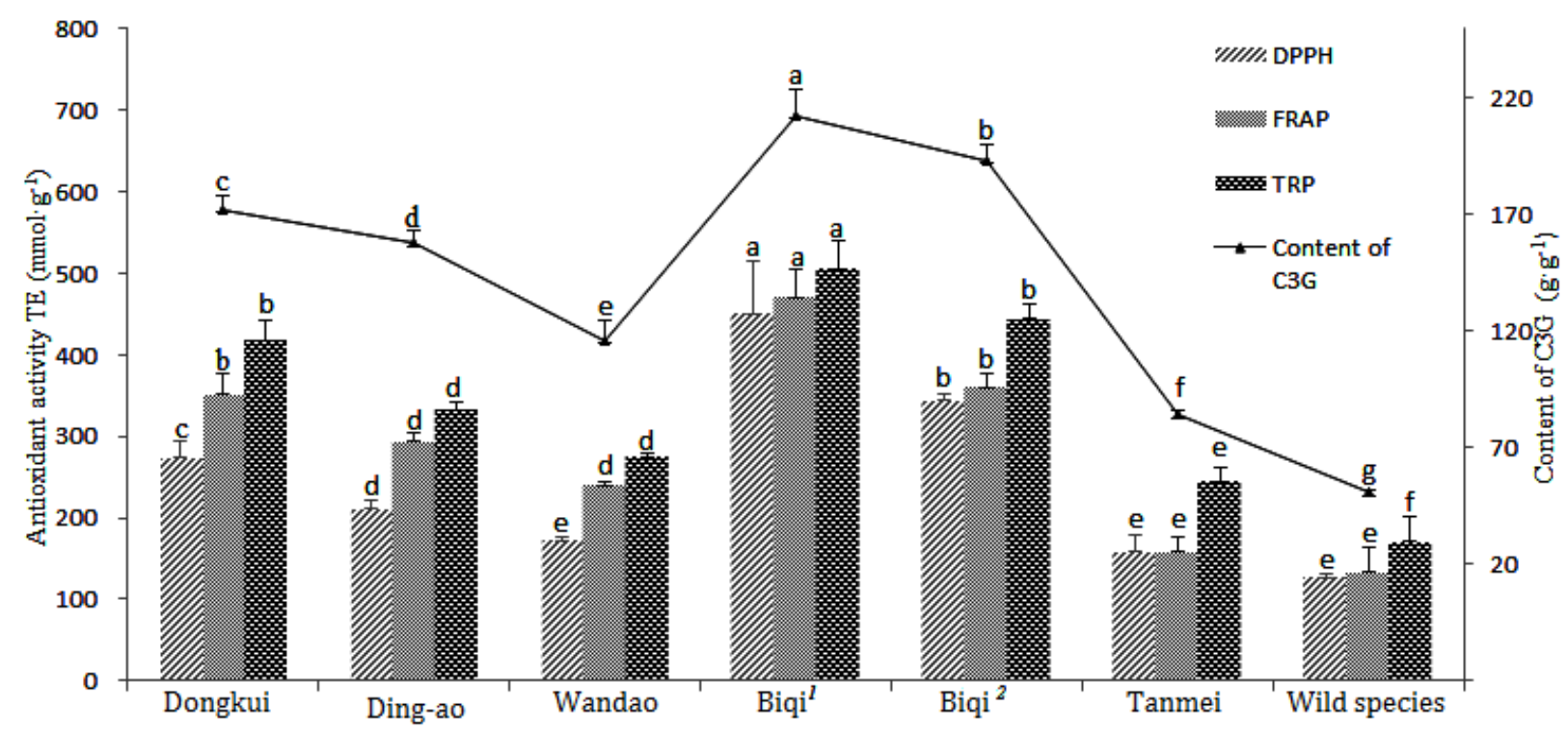

Figure 2. Contents of C3G and antioxidant capacity (TE) of PAEs. Different letters mean significant differences $(\mathrm{p}<0.05)$

\subsection{Antifungal Activity}

We evaluated the antifungal capability of PAEs and EKs with slant-face-tube method, and the results (Table 2) showed that EKs exhibited effective antifungal capability against sample fungus except Botrytis cinerea and Fusariumoxysporum f. sp. Vasinfectum with MIC values ranging from 0.5000 to $0.0625 \mathrm{mg} \cdot \mathrm{mL}^{-1}$. Thus it could be seen that Myricarubra kernel was a good source of lowpriced botanical fungicide. At the same time, restraint activities of PAEs were not found.

\subsection{Cytotoxic Activity}

In previous brine shrimp lethality assay, estimating the cytotoxicity of compounds, monomers with $\mathrm{LC}_{50}$ less than $100 \mu \mathrm{g} \cdot \mathrm{mL}^{-1}$ and crude extracts with $\mathrm{LC}_{50}$ less than 500 $\mu \mathrm{g} \cdot \mathrm{mL}^{-1}$ were deemed to be cytotoxic. As shown in Table 3 , PAEs from bayberries distributed their $\mathrm{LC}_{50}$ from $500-$ $1000 \mu \mathrm{g} \cdot \mathrm{mL}^{-1}$, which showed that there was little or none antifungal activity or cytotoxicity inthe extracts of Myricarubra and anthocyanidin. These research results were strong evidence of the feasibility and safety for these extracts to be developed as food additives and health-care food.

On the contrary, the results showed that a strong cytotoxicity was potent in EKs and no cytotoxicity in PAEs. LC $_{50}$ of EKs and PAEs ranged from tens to hundreds. The $\mathrm{LC}_{50}$ of wild species of the bayberry kernels with highest potent cytotoxic activity was equivalent to numerous potent cytotoxic monomers in previous researches. Moreover, previous researches confirmed that cytotoxic substances could specifically inhibit tumor-cell proliferation, which indicated a promising future as it is cheap and easy to obtain, and it solved the waste-disposal problem in bayberry food industry. However, no obvious correlation between EKs' cytotoxicity and flavonoids or phenolic acids compounds was found, so the mechanisms of EKs' cytotoxicity should be further studied.

Table 2. Antifungal activities and MIC $\left(\mathrm{mg} \cdot \mathrm{mL}^{-1}\right)$ values of EKs

\begin{tabular}{|c|c|c|c|c|c|c|c|c|}
\hline & $\begin{array}{c}\text { Fusarium } \\
\text { graminearum } \\
\text { Schwabe }\end{array}$ & $\begin{array}{c}\text { Fusarium } \\
\text { graminearum }\end{array}$ & $\begin{array}{c}\text { Exerohilum } \\
\text { turcicum } \\
\text { Pass }\end{array}$ & $\begin{array}{c}\text { Rhizoctonia } \\
\text { solani } \\
\text { Kühn }\end{array}$ & $\begin{array}{l}\text { Botrytis } \\
\text { cinerea }\end{array}$ & $\begin{array}{l}\text { Valsa } \\
\text { mali }\end{array}$ & $\begin{array}{c}\text { Sclerotinia } \\
\text { sclerotiorum }\end{array}$ & $\begin{array}{c}\text { Fusarium } \\
\text { oxysporumf. } \\
\text { sp. vasinfectum }\end{array}$ \\
\hline Dongkui & 0.1250 & 0.1250 & 0.2500 & 0.5000 & $\mathrm{a}$ & 0.2500 & 0.1250 & $\mathrm{a}$ \\
\hline Wandao & 0.2500 & 0.2500 & 0.0625 & 0.1250 & a & 0.2500 & 0.2500 & 0.1250 \\
\hline Biqi $^{1}$ & 0.1250 & 0.2500 & 0.2500 & 0.2500 & a & 0.2500 & 0.2500 & 0.5000 \\
\hline Biqi $^{2}$ & 0.2500 & 0.2500 & 0.2500 & 0.5000 & a & 0.5000 & 0.2500 & a \\
\hline Tanmei & 0.2500 & 0.2500 & 0.2500 & 0.2500 & a & 0.5000 & 0.5000 & 0.5000 \\
\hline Shuijing & 0.2500 & 0.5000 & 0.5000 & 0.2500 & a & 0.2500 & 0.1250 & 0.2500 \\
\hline Wild species & 0.0625 & 0.0625 & 0.2500 & 0.1250 & 0.5000 & 0.5000 & 0.1250 & 0.2500 \\
\hline
\end{tabular}

${ }^{\mathrm{a}}$ means mycelial growth were all observed in three tubes

Table 3. The cytotoxicity of EKs (extracts from kernels) and PAEs

\begin{tabular}{cccc}
\hline EKs & $\mathrm{LC}_{50}\left(\mu \mathrm{L} \cdot \mathrm{mL}^{-1}\right)$ & PAEs & $\mathrm{LC}_{50}\left(\mu \mathrm{L}^{-1} \mathrm{~mL}^{-1}\right)$ \\
\hline Dongkui & 180 & Dongkui & 759 \\
Ding-ao & 128 & Ding-ao & 1038 \\
Wandao & 58 & Wandao & 521 \\
Biqi $^{1}$ & 134 & Biqi $^{1}$ & 769 \\
Biqi $^{2}$ & 195 & Biqi $^{2}$ & 670 \\
Tanmei $^{2}$ & Tanmei & 463 \\
Shuijing & 72 & Shuijing & ND \\
Wild species & 316 & Wild species & 803 \\
\hline
\end{tabular}




\subsection{Antifatigue Activity}

Resent research showed that anthocyanins of mulberry juice purification which contained two kinds of anthocyanin and one of them was C3G, possessed an antifatigue effect and an increased endurance capacity [23]. Therefore, in this paper, the loaded swimming experiment, the most direct, objective criterion for reflecting physical endurance, was designed to authenticate whether PAEs had such an activity as well, and whether C3G played a major role in it. The results (Figure 3) of the testing indicated that PAEs helped to prolong the time of mice-loaded swimming: The higher dose groups with Biqi ${ }^{1}$ PAEs could significantly prolong the time of mice-loaded swimming, while the low and medium-dosage groups could also increase the swimming time to a certain extent. Thus it can be seen that: Biqianthocyanins have vast development future when used as the food additives.

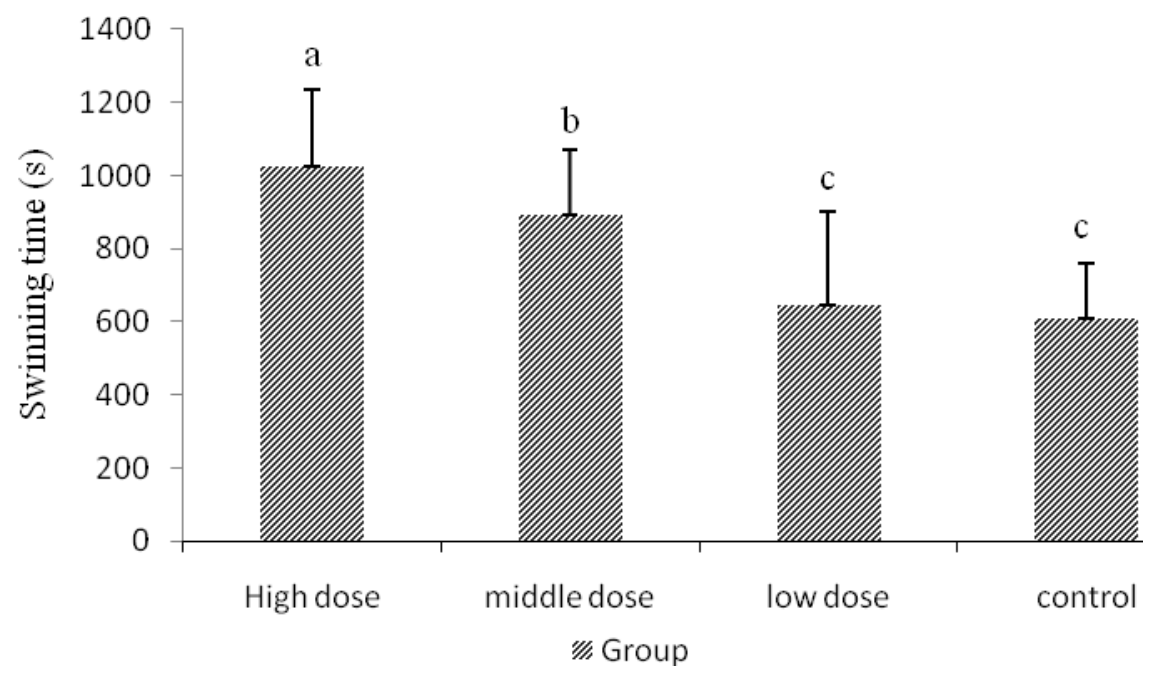

Figure 3. Effect of PAEs of Biqi ${ }^{1}$ on the swimming time in mice. The error bars represent one standard deviation. Different letters indicate significant differences between groups $(\mathrm{P}<0.05)$

\section{Conclusion}

As the most important two parts of the industrial waste from processing Myricarubra, the residue and kernels have huge value and potential commercial application. The residue is rich in anthocyanins and C3G, and it has strong effects on antioxidation and fatigue resistance without any sugar and toxicity. It could be used as food additives and dietary supplement. On the other hand, kernels with high cytotoxic and antifungal activities bring health and medical value. This industrial waste deserves to be recycled and further developed

\section{List of Abbreviations}

C3G: cyanidin-3-O-glucoside

DPPH: 1, 1-diphenyl-2-picrylhydrazyl

TE: mmol Trolox equivalents

FRAP: ferric reducing antioxidant power

TPTZ: 2, 4, 6-tris (2-pyridyl)-s-triazine

PDA: potato dextrose agar

PAEs: purified anthocyanins extracts

EKs: extracts from kernel

TRP: total reducing power

MIC: minimalinhibitory concentration

\section{Reference}

[1] Renata ASS, Pastore G.M. Evaluation of the effects of anthocyanins in type 2 diabetes. Food Research International, 46. 378-386. 2012.
[2] Guo H, Ling W, Wang Q, Liu C, Hu Y, Xia M, Feng X, Xia X.Effect of anthocyanin-rich extract from black rice (Oryza sativa L. indica) on hyperlipidemia and insulin resistance in fructose-fed rats. Plant Foods for Human Nutrition, 62. 1-6. 2007.

[3] Nizamutdinova IT, Jin YC, Chung J, Shin SC, Lee SJ, Seo HG, Lee JH, Chang KC, Kim HJ.The anti-diabetic effect of anthocyanins in streptozotocin-induced diabetic rats through glucose transporter 4 regulation and prevention of insulin resistance and pancreatic apoptosis. Molecular Nutrition and Food Research, 53. 1419-1429. 2009.

[4] Grace MH, Ribnicky DM, Kuhn P, Poulev A, Logendra S, Yourself GG, Raski I, Lila MA. Hypoglycemic activity of a novel anthocyanin-rich formulation from low bush blueberry, Vacciniumangustifolium Aiton. Phytomedicine, 16. 406-415. 2009

[5] Feshani AM, Kouhsar SM, Mohammadi S. Vacciniumarctostaphylos, a common herbal medicine in Iran: Molecular and biochemical study of its antidiabetic effects on alloxan-diabetic Wistar rats. Journal of Ethnopharmacology, 133. 67-74. 2011.

[6] Huang HP, Chang YC, Wu CH, Hung CN, Wang CJ. Anthocyanin-rich Mulberry extract inhibit the gastric cancer cell growth in vitro and xenograft mice by inducing signals of p38/p53 and c-jun. Food Chemistry, 129, 1703-1709. 2011.

[7] Bridle P, Timberlake CF. Chemical analysis and screening as anticancer agent of anthocyanin-rich extract from uvacaimarona (Pouroumacecropiifolia Mart.) fruit. Journal of Agricultural and Food Chemistry, 58. 2100-2110. 2010.

[8] Sun C, Zheng Y, Chen Q, Tang X, Jiang M, Zhang J, Li X, Chen K. Purification and anti-tumour activity of cyanidin-3-O-glucoside from Chinese bayberry fruit. Food Chemistry, 131. 1287-1294. 2012.

[9] Guo H, Guo J, Jiang X, Li Z, Ling W. Cyanidin-3-O- $\beta$-glucoside, a typical anthocyanin, exhibits antilipolytic effects in 3T3-L1 adipocytes during hyperglycemia: Involvement of FoxO1mediated transcription of adipose triglyceride lipase. Food Chemical Toxicology, 50. 3040-3047. 2012.

[10] Guo H, Xia M, Zou T, Ling W, Zhong R, Zhang W. Cyanidin 3glucoside attenuates obesity-associated insulin resistance and hepatic steatosis in high-fat diet-fed and $\mathrm{db} / \mathrm{db}$ mice via the transcription factor FoxO1. Journal of Nutritional Biochemistry, 23. 349-360. 2012. 
[11] Li CY, Xu HD, Zhao BT, Chang HI, Rhee HI. Gastroprotective effect of cyanidin 3-glucoside on ethanol-induced gastric lesions in rats. Alclhol, 42. 683-687. 2008.

[12] Zhou SH, Fang ZX, Lue Y, Chen JC, Liu DH, Ye XQ. Phenolics and antioxidant properties of bayberry (Myricarubra Sieb. et Zucc.) Pomace. Food Chemistry, 112. 394-399. 2009.

[13] Fang Z, Zhang Y, Lue Y. Phenolic compounds and antioxidant capacities of bayberry juices. Food Chemistry, 113. 884-888.2009.

[14] Skrede G, Wrolstad RE, Durst RW. Changes in anthocyanins and polyphenolics during juice processing of high bush blueberries (Vacciniumcorymbosum L.). Journal of Food Science, 65. 357-364. 2000.

[15] Bridle P, Timberlake CF. Anthocyanins as natural food coloursselected aspects. Food Chemistry, 58. 103-109. 1995.

[16] Chen XT, Yuan K, Liu HL. Phenolic contents and antioxidant activities in ethanol extracts of Citrusreticulata Blanco cv. Ougan fruit. Journal of Food Agriculture and Environment, 8. 150-155. 2010.

[17] Benzie IFF, Strain JJ. The ferric reducing ability of plasma (FRAP) as a measure of "antioxidant power": The FRAP Assay. Analytical Biochemistry, 239. 70-76. 1996.

[18] Oyaizu M. Studies on products of browning reactions: antioxidative activities of browning reaction products prepared from glucosamine. Japan Journal of Nutrition, 44. 307-315.1986.
[19] Li XJ, Zhang Q, Zhang AL, Gao JM. Metabolites from aspergillusfumigatus, an endophytic fungus associated with Meliaazedarach, and their antifungal, antifeedant, and toxic activities. Journal of Agricultural and Food Chemistry, 60. 34243431. 2012.

[20] Yang SX, Yu ZC, Lu QQ, Shi WQ, Laatsch H, Gao, JM.Fusaroside, a unique glycolipid from Fusarium sp., an endophytic fungus isolated from Meliaazedarach. Organic and Biomolecular Chemistry, 10. 819-824. 2011.

[21] You LJ, Zhao MM, Regenstein JM, Ren JY, In vitro antioxidant activity and in vivo anti-fatigue effect of loach (Misgurnusanguillicaudatus) peptides prepared by papain digestion. Food Chemistry, 124. 188-194. 2011.

[22] Bao JS, Cai YZ, Sun M.Anthocyanins, flavonols, and free radical scavenging activity of Chinese bayberry (Myricarubra) extracts and their color properties and stability. Journal of Agricultural and Food Chemistry, 53. 2005, 2327-2332.

[23] Jiang DQ, Guo Y, Xu DH, Huang YS, Yuan K, Lv ZQ. Antioxidant and anti-fatigue effects of anthocyanins of mulberry juice purification (MJP) and mulberry marc purification (MMP) from different varieties mulberry fruit in China. Food and Chemical Toxicology, 50. 1-7. 2013. 